\title{
LESÕES EM ATLETAS DE MONTARIA EM TOURO E PREVENÇÃO POR MEIO DE PREPARO FISICO
}

\section{Dora Castro Agulhon Segura}

Departamento de Fisioterapia da Universidade Paranaense (UNIPAR), Umuarama (PR), Brasil.

\section{Jéssica da Silva Sena}

Discente de Fisioterapia da Universidade Paranaense (UNIPAR), Umuarama (PR), Brasil.

E-mail: dora@unipar.br
RESUMO: A montaria em touro é um esporte equestre com elevado risco de lesão, o que torna imprescindível o preparo físico como forma de prevenção mesmo diante da obrigatoriedade dos equipamentos de segurança. Desta forma, o objetivo deste estudo foi analisar quais são as lesões mais comuns nos atletas de montaria em touro e informar sobre os benefícios do preparo físico como meio de prevenção. Para tanto, foram selecionados 44 atletas do gênero masculino participantes da competição de montaria em touro na $30^{\mathrm{a}}$ Festa do Peão de Boiadeiro da cidade de Ouro Verde - Paraná, os quais responderam um questionário sobre a importância do preparo físico e o índice de lesões ocorridas durante as competições. Os resultados indicaram que a maioria das lesões $(53,33 \%)$ ocorreu durante o tempo em que o atleta permaneceu sobre o animal. Nessa posição, alesão mais referida pelos atletas (13,33\%) foi a distensão muscular em região de braço. Já a lesão com maior incidência no momento do desmonte do animal foi a luxação no ombro (10,47\%), capaz de deixar o atleta afastado das competições por um período significativo. Referiu-se que preparo físico com acompanhamento profissional influencia de forma significativa no rendimento dos atletas, reduzindo o risco de lesões e, consequentemente, o tempo fora de competições, sendo que os atletas que não possuem acompanhamento profissional durante o preparo físico demonstraram ter $33 \%$ a mais de chances de apresentarem algum tipo de lesão.

PALAVRAS-CHAVE: Atletas; Fisioterapia; Lesões; Prevenção.

\section{LESIONS IN BULL-RIDING ATHLETES AND THEIR PREVENTION BY PHYSICAL TRAINING}

\footnotetext{
ABSTRACT: Bull-riding is a sport with high lesion occurrences. It requires physical training for their prevention even when the indispensable safety equipments are used. Current analysis lists the most common lesions in bull-riding athletes and provides the benefits of physical training. Forty-four male athletes who participated in bull-riding competitions at the Thirtieth Cowboy Feast in Ouro Verde PR Brazil, were selected. They answered a questionnaire on the importance of physical training and on lesion index during competitions. Results showed that most lesions (53.33\%) occurred during the time the athlete was mounted on the animal. The lesion most referred to by athletes (13.33\%) was muscle distension of the arm. The lesion with the highest occurrence during riding down the animal was dislocation of the shoulder (10.47\%), which would cause the athlete quitting competitions for a significant period. The athletes also underscored that physical preparation by a professional person affected significantly the athletes' performance, with a reduction of lesions and time away from competitions. Athletes without any professional assistance during physical training have a 33\% more chance in acquiring lesions.
} 
KEY WORDS: Athletes; Physiotherapy; Lesions in Athletes; Prevention.

\section{INTRODUÇÃO}

De acordo com Meyers e Laurent (2010a), o rodeio originou-se na Espanha pelos vaqueiros espanhóis em 1700, último ano do século XVII. Somente chegou às Américas por meio dos espanhóis que colonizaram o México, tendo sido aderido pelos mexicanos durante o século XVIII. Logo após a guerra com os americanos, começou a ser praticado pelos colonos norte-americanos, época de doma de animais e festas mexicanas que originaram os rodeios atuais. Durante essas festas que aconteciam em fazendas e ranchos do interior do país praticavase a montaria em cavalos como meio de entretenimento (SERRA; TUBINO; NOVAES, 2003).

Segundo Branício (2012), devido à guerra passaram a pertencer aos Estados Unidos alguns estados inteiros, como a Califórnia e outros do velho oeste. A partir daí, tanto pela divisa quanto pela proximidade com o México, hábitos de ambos os países acabaram sendo incorporados um ao outro surgindo assim os rodeios. Também foram os norte-americanos que organizaram os rodeios como esporte com competições e regras.

Em 1980 chegou ao Brasil a modalidade montaria em touros, tendo a partir daí se tornado uma das maiores atrações das festas de rodeio. Em 2001 essa modalidade passou a ser reconhecida como esporte regulamentado de acordo com a Lei $n^{0} 10.220$, de 11 de abril de 2001. Posteriormente, em 2002, um novo projeto de lei (116/2001) exigiu que os organizadores de tais eventos disponibilizassem peões auxiliares, ambulâncias e médicos do mesmo modo que requer do atleta participante um seguro de vida (DOIMO; JIMENEZ, 2007).

Este esporte é famoso pela agilidade, equilíbrio, força muscular e coragem com que os competidores encaram os animais treinados. Durante a competição o atleta precisa manter-se por oito segundos sobre o animal, equilibrando-se com apenas uma mão em uma corda, enquanto a outra mão dever ser mantida para cima a fim de impedir o contato da mesma com o animal ou com a cerca evitando a desclassificação do atleta (MEYERS; STERLING; SOURYAL, 2003).

Os elementos que desencadeiam a desclassificação incluem: encostar a mão levantada do atleta na cerca ou no animal e utilizar aparatos que provoquem danos físicos ou maus-tratos aos animais. A pontuação é concedida conforme os seguintes critérios: dificuldade e estilo da montaria, movimentos do animal e controle do peão sobre o animal. A enorme diferença de peso e força entre os animais e os atletas submete o atleta, na maioria das vezes, a um extremo estresse físico que pode levar a inúmeras lesões. Contudo, mesmo com toda a evolução nas últimas décadas, com presença de juízes especializados em análise de montarias, animais treinados e prêmios para os vencedores das provas, ainda é raro um programa de treinamento exclusivo para desenvolver as atividades específicas para o rodeio competitivo (BERGMASCHI; MATSUDO; MATSUDO, 2006).

Branício (2012) descreve que os itens obrigatórios de segurança para a prática do esporte são colete, calça de couro, espora e luva, e como equipamentos opcionais o capacete e o protetor bucal. A montaria em touro é tida como a prova mais radical do rodeio, além de ser a que mais exige preparo físico e mental do atleta, havendo um alto risco de acidentes com fraturas e contusões e correr até mesmo o risco de morrer. Nessa modalidade não se usa sela e sim apenas uma corda americana que é onde o atleta com apenas uma das mãos se equilibra sobre o animal.

De acordo com Serra, Tubino e Novaes (2003), o melhor touro para as competições de rodeio é proveniente de um cruzamento entre as raças Nelore e Marchigiana, devido à agilidade e à violência do Nelore $\mathrm{e}$ ao porte do Marchigiana. A partir desse cruzamento se consegue um animal de bom porte, bravo e ágil, capaz de pular cerca de treze vezes em apenas oito segundos.

Meyers e Laurent (2010a) descrevem que competições de rodeio são muito conhecidas por meio da sua atmosfera de alto impacto. Avaliado por muitos como um esporte ousado, com elevada exposição a lesões e traumas frequentes, as situações onde há o contato humano/animal compreendem a $80 \%$ das lesões apresentadas com traumas em região torácica, abdominal, cadeia posterior de tronco e articulações como ombro e joelho. Os traumas graves incluem rupturas ligamentares, fraturas, luxações, subluxações, pneumotórax, concussões e neuropraxias diversas.

Doimo e Jimenez (2007) descreveram que os segmentos corporais mais acometidos em atletas de montaria em touro foram as coxas, joelhos e ombros. Uma 
vez que a montaria em touro é considerada um esporte perigoso exigindo um elevado grau de habilidade do atleta, se faz importante observar e avaliar sob diferentes enfoques os dados referentes às lesões para se elaborar mecanismos de prevenção e uma eficaz minimização de riscos e sequelas decorrentes da prática desse esporte.

Para Meyers e Laurent (2010b), os principais mecanismos de lesões são decorrentes da idade, imaturidade física, fadiga, experiência, comportamento, peculiaridade violenta do esporte e déficit de intervenção médica apropriada. Quando há um plano de treino traçado especialmente para o esporte específico, o condicionamento maximiza o potencial atlético, minimizando a predisposição a lesões além de tornar mais rápida a recuperação.

De acordo com Powers e Howley (2009) e Branício (2012), fica claro que o uso do preparo físico com técnicas adequadas de treinamento minimizam significativamente o número de lesões sofridas, pois melhora a flexibilidade e resistência orgânica exigidas na ocasião de se manter em cima do touro, diminuindo a quantidade de acidentes mais graves.

Sendo assim, o presente estudo teve como objetivo analisar quais são as lesões mais comuns nos atletas de montaria em touro e informar sobre os benefícios do preparo físico como meio de prevenção.

\section{METODOLOGIA}

Foram selecionados 44 atletas de montaria em touro, do gênero masculino, sem fator de idade e peso, que participaram da $30^{\mathrm{a}}$ Festa do Peão de Boiadeiro de Ouro Verde do Oeste, que aconteceu no período de 30 de abril a 03 de maio de 2015, na cidade de Ouro Verde do Oeste, Estado do Paraná.
Os critérios de seleção envolveram os atletas que competiam na modalidade montaria em touro que sofreram ou não algum tipo de lesão relacionada à prática esportiva independente de realizarem ou não algum tipo de preparo físico.

Os critérios de exclusão englobaram os atletas de montaria em cavalo e os salva-vidas.

A coleta de dados foi efetivada por meio da aplicação de um questionário composto por 16 questões que abordaram o conhecimento do atleta em relação à importância do preparo físico e o índice de lesões ocorridas durante as competições.

Após a coleta de dados, os resultados foram tabulados, foram calculadas as médias e os desvios padrão e realizada a análise estatística descritiva percentual.

Todos os participantes assinaram o Termo de Consentimento Livre e Esclarecido e o estudo foi aprovado pelo Comitê de Ética envolvendo seres humanos da Universidade Paranaense, sob o protocolo de número $1.087 .015 / 2015$.

\section{RESULTADOS}

Foram avaliados 44 atletas do gênero masculino, com média de idade de 27,11 ( $\pm 4,35)$ anos, a menor idade foi 20 anos e a maior idade foi 37 anos. A média de peso foi de $72,06 \mathrm{~kg}( \pm 8,05)$, sendo o menor peso de 60 $\mathrm{kg}$ e o maior peso $90 \mathrm{~kg}$.

Foi constatado que a maioria dos entrevistados (97,72\%) realizava algum tipo de atividade física como meio de preparo físico para as competições, enquanto $2,27 \%$ não realizavam nenhum tipo de preparo físico. As atividades realizadas eram musculação, alongamentos, corrida, futebol, além de outras (Gráfico 1).

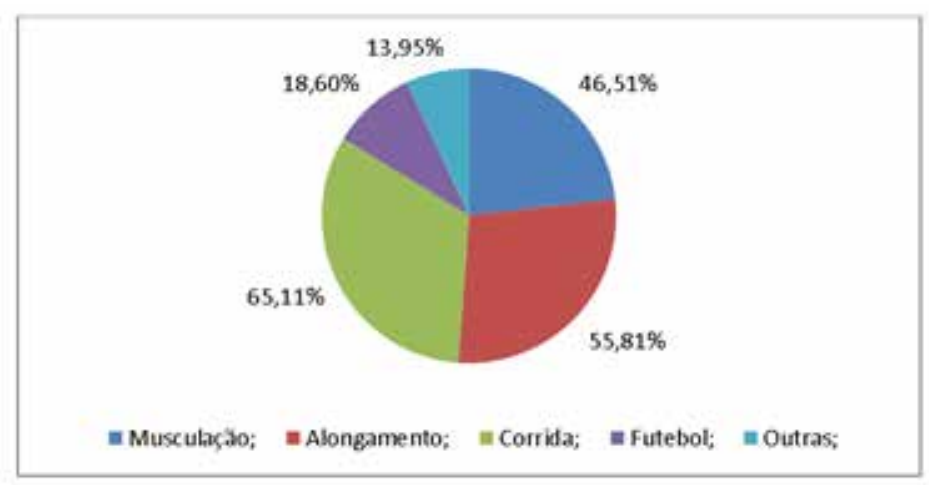

Gráfico 1. Atividades realizadas como forma de preparo para as competições 
Verificou-se que a atividade mais realizada era a corrida (65,11\%), seguida dos alongamentos (55,81\%), musculação (46,51\%), futebol (18,60\%) e posteriormente outras atividades que envolveram natação, muay thay, treino de montarias e treino de prova de laço $(13,95 \%)$.

Constatou-se também que a maioria dos atletas praticava pelo menos dois tipos de atividades (40,90\%), enquanto $29,54 \%$ praticavam apenas um tipo de atividade física, e $24,99 \%$ praticavam três tipos de atividade fí- sica, seguidos por $2,27 \%$ que praticavam quatro tipos de atividade física regularmente.

Do total de atletas que realizavam preparo físico, $29,54 \%$ realizavam preparo físico duas vezes por semana, $27,27 \%$ realizavam três vezes por semana, que se igualou aos $27,27 \%$ que realizavam quatros vezes por semana, seguidos por $13,63 \%$ que realizavam preparo físico diariamente (Gráfico 2).

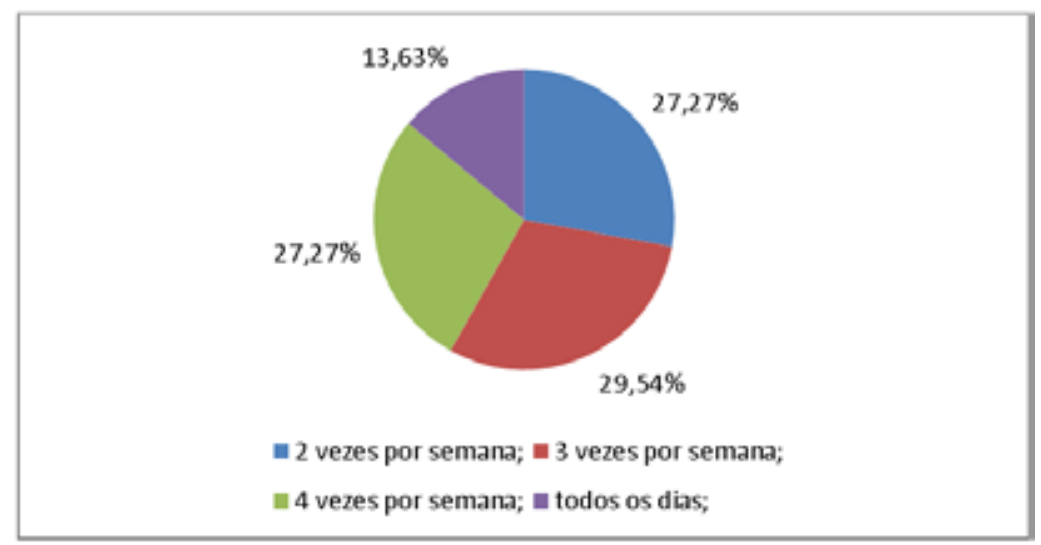

Gráfico 2. Frequência com que se realizava preparo físico

Dos atletas que realizavam preparo físico somente $34,50 \%$ tinham acompanhamento profissional, enquanto 58,21\% não tinham o acompanhamento de um profissional durante os treinos; sendo que 19,40\% tinham acompanhamento de um educador físico, 6,46\% acompanhamento de um fisioterapeuta, $4,31 \%$ de um médico e 2,15\% de um massoterapeuta, no entanto, 2,15\% tinham acompanhamento de um educador físico e de um fisioterapeuta simultaneamente.

Entre os atletas participantes da pesquisa $93,18 \%$ consideravam importante a presença de um fisioterapeuta tanto durante os treinos como durante as competições, em contrapartida $6,81 \%$ não consideravam importante a presença de um fisioterapeuta.

Somente $38,63 \%$ dos atletas relataram ter participado de competições onde havia a presença de um fisioterapeuta, a maioria, que perfazia $61,36 \%$ dos atletas, relatou não ter participado de nenhuma competição onde havia um fisioterapeuta.
Quando questionados sobre o uso de equipamentos de proteção individual (EPI) $100 \%$ dos atletas responderam que usavam algum tipo de EPI. Foi possível verificar que 29,54\% dos atletas usavam somente os EPIs obrigatórios (calça de couro, colete, espora e luva), 25\% utilizavam capacete além dos itens obrigatórios, $25 \%$ utilizavam o protetor bucal além dos EPIs obrigatórios, enquanto $20,45 \%$ utilizavam capacete e protetor bucal além dos EPIs obrigatórios.

Durante o tempo em que o atleta tentou se manter em cima do touro $88,63 \%$ dos atletas sofreram algum tipo de lesão, já 11,36\% dos atletas relataram não ter sofrido nenhum tipo de lesão durante esse período.

As lesões que mais acometeram os atletas durante o período em que permaneceram em cima do touro foram fraturas (41,66\%), distensões musculares (31,66\%), luxações $(19,16 \%)$, rupturas musculares $(4,16 \%)$, rupturas tendíneas $(2,50 \%)$ e bursites $(0,83 \%)$ (Gráfico 3). 


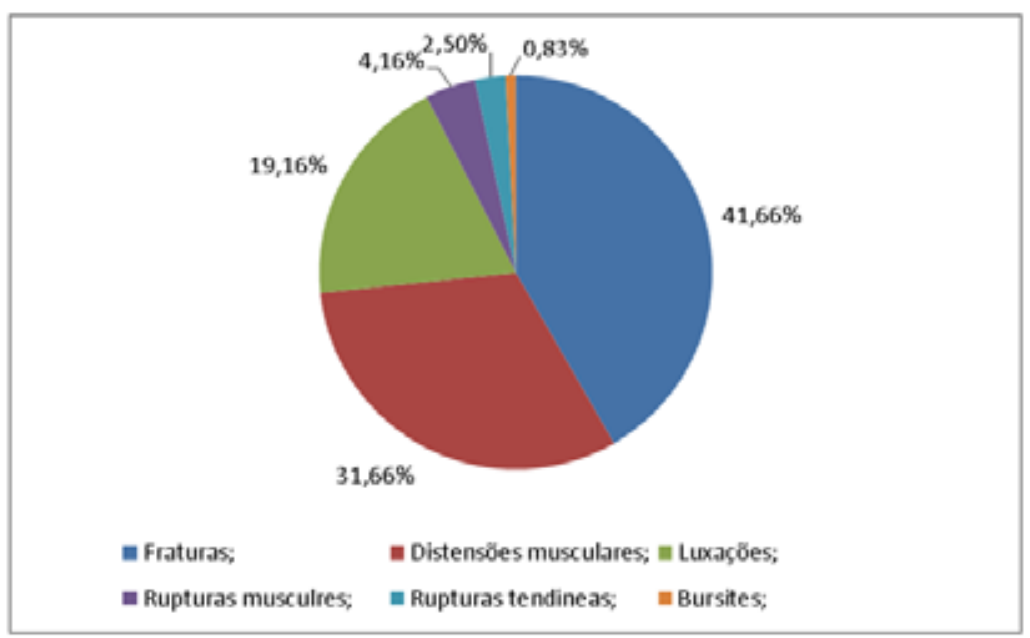

Gráfico 3. Índice das lesões mais comuns durante a permanência dos atletas em cima do touro

Do total de lesões referidas, a lesão que mais acometeu os atletas durante o período em que deveriam se manter em cima do touro foi a distensão muscular na região do braço (13,33\%); seguida por distensão muscular em região de ombro (11,42\%); distensão muscular em região de coxa $(7,50 \%)$; luxação no ombro $(6,66 \%)$; fratura em região de pé $(5,83 \%)$; fratura na região do joelho (5\%); fratura em região de perna (5\%); luxação de arcos costais $(3,33 \%)$; fratura em região de cotovelo $(3,33 \%)$; fratura em região de punho (3,33\%); fratura em região de mão $(3,3 \%)$; fratura de tornozelo (3,33\%); distensão muscular em região de antebraço (2,50\%); distensão muscular em região de arcos costais (2,50\%); luxação no punho (2,50\%); ruptura muscular em região de perna $(2,50 \%)$; fratura em região de ombro $(2,50 \%)$; e fratura em arcos costais $(2,50 \%)$.

Os últimos dados registraram distensão muscular em região de perna (1,66\%); luxação em região de mão $(1,66 \%)$; luxação no joelho $(1,66 \%)$; luxação em re- gião de pé (1,66\%); ruptura muscular em região de braço (1,66\%); fratura em região de braço (1,66\%); fratura em região de coluna (1,66\%); fratura em região de quadril (1,66\%); fratura em região de coxa (1,66\%); distensão muscular em região de pescoço $(0,83 \%)$; luxação no cotovelo $(0,83 \%)$; luxação no quadril $(0,83 \%)$; ruptura tendínea em região de ombro $(0,83 \%)$; ruptura tendínea em região de cotovelo $(0,83 \%)$; ruptura tendínea em região de joelho $(0,83 \%)$; bursite no cotovelo $(0,83 \%)$; e fratura no maxilar $(0,83 \%)$.

Dos atletas participantes da pesquisa $72,72 \%$ relataram ter sofrido alguma lesão ao cair de cima do touro, enquanto $27,27 \%$ afirmaram nunca ter sofrido lesão durante a queda.

De acordo com o Gráfico 4, os tipos de lesões que mais acometeram os atletas ao caírem de cima do touro foram fraturas $(57,14 \%)$, luxações $(21,90 \%)$, entorses $(10,47 \%)$, escoriações e rupturas tendíneas $(1,90 \%)$.

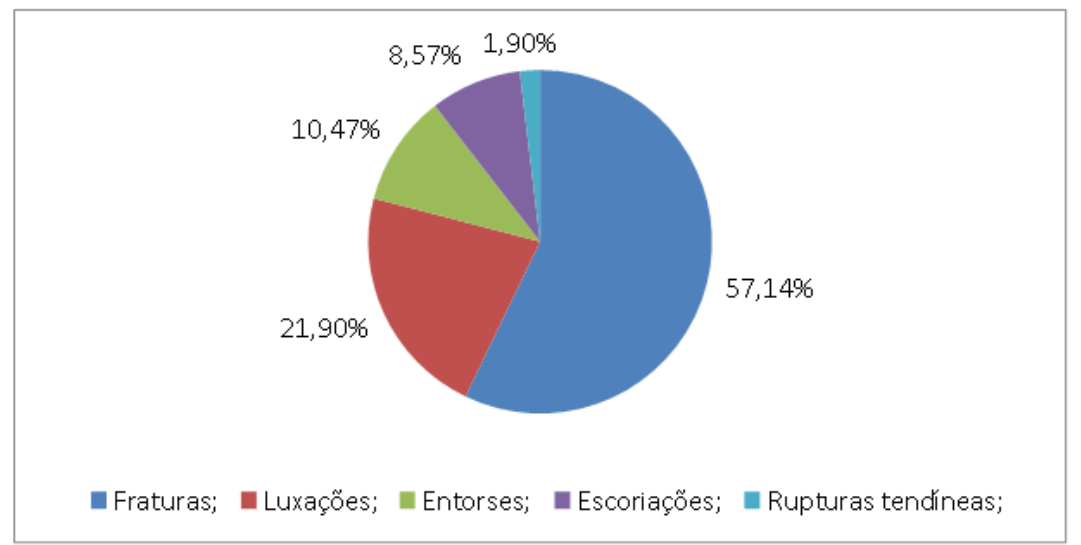

Gráfico 4. Índice das lesões mais comuns quando os atletas sofreram queda do animal 
Porém, dentre os tipos de lesões referidas à luxação de ombro, foi possível descrever 10,47\% dos casos; seguida da entorse de tornozelo (6,66\%); fratura em região de ombro $(5,71 \%)$; fratura em região de braço $(5,71 \%)$; fratura em região de mão $(5,71 \%)$; fratura em arcos costais $(5,71 \%)$; fratura em região de perna $(5,71 \%)$; fratura em região de punho (4,76\%); fratura em região de pé (4,76\%); entorse de tornozelo (repetição?) $(3,80 \%)$; fratura em região de crânio (3,80\%); fratura em região de coxa $(3,80 \%)$; escoriação em região de mão $(2,85 \%)$; fratura em região de cotovelo $(2,85 \%)$; fratura em região de coluna $(2,85 \%)$; luxação no punho $(2,85 \%)$; luxação dos arcos costais (2,85\%); luxação no joelho (2,85\%); escoriação em região de pescoço $(1,90 \%)$; fratura em região de antebraço (1,90\%); fratura em região de tornozelo (1,90\%); luxação no cotovelo (1,90\%); ruptura tendínea em região de joelho (1,90\%); escoriação em região de crânio $(0,95 \%)$; escoriação em região de braço $(0,95 \%)$; escoriação em região de coxa $(0,95 \%)$; escoriação em região de perna $(0,95 \%)$; fratura em região de quadril $(0,95 \%)$; fratura em região de joelho ( $0,95 \%)$; e luxação em região de mão $(0,95 \%)$.

Foi notório que as lesões demonstraram maior predominância durante o período em que o atleta deveria manter-se em cima do animal (53,33\%) quando comparadas com as lesões ocorridas no momento em que o atleta desmontava do animal (46,66\%) (Gráfico 5).

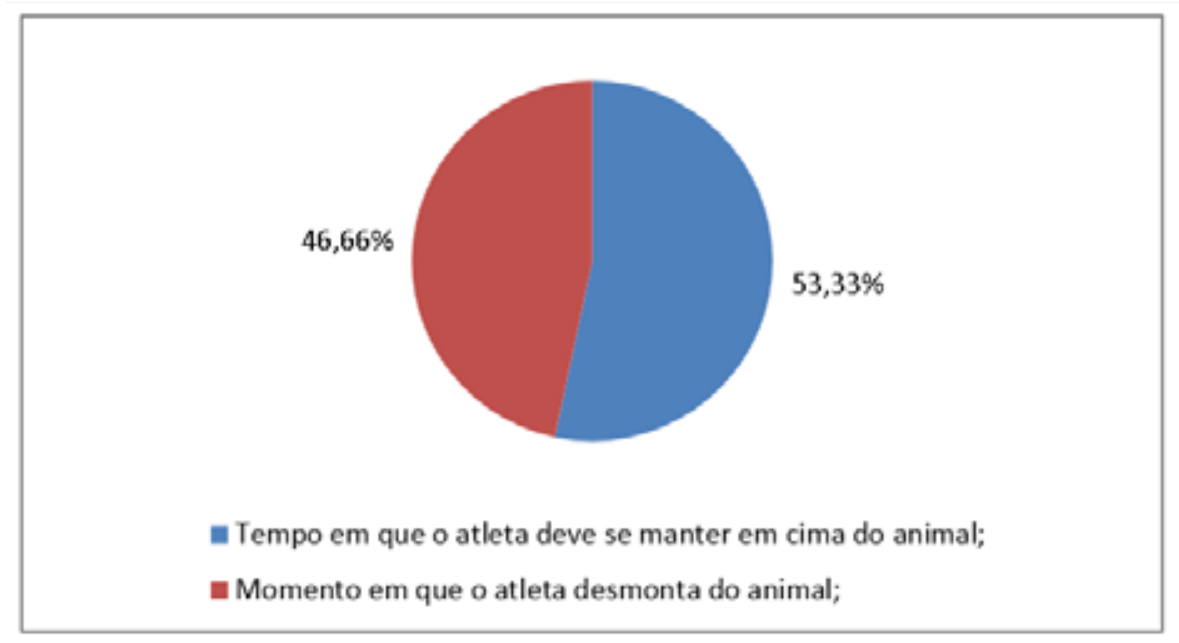

Gráfico 5. Momento em que ocorreram mais lesões

Também foi possível observar que os atletas que tinham acompanhamento profissional durante o preparo físico $(37,20 \%)$ apresentaram uma média de 4 lesões por atleta, enquanto que os atletas que não tinham acompanhamento profissional durante o preparo físico $(62,79 \%)$ apresentaram uma média de 6 lesões por atleta. Assim sendo, os atletas que não possuíam acompanhamento profissional durante o preparo físico tenderam a ter $33 \%$ a mais de chances de apresentar algum tipo de lesão quando comparados com os atletas que possuíam acompanhamento profissional.

\section{DISCUSSÃO}

No presente estudo verificou-se nos atletas uma média de idade de 27,11 anos e uma média de peso de
$72,06 \mathrm{~kg}$. O estudo de Doimo e Jimenez (2007), que avaliou o índice de lesões em atletas de montaria em touros, constatou uma média de idade de 24,5 anos. Já no estudo de Lau et al. (2013), que descreveu sobre as lesões de ruptura de peitoral maior em atletas de rodeio, foi apresentada uma média de idade de 35 anos. O estudo de Bergamaschi, Matsudo e Matsudo (2006), que verificou a relação da força de membros superiores e o nível de atividade física com prevalência de lesão e o desempenho de participantes de rodeio competitivo, demonstrou uma média de idade de 23,2 anos. Já o estudo de Souza et al. (2011), sobre a capacidade de força dos membros superiores em competidores de montaria em touros, apresentou um média de idade de 24,7 anos e uma média de peso de $78,9 \mathrm{~kg}$ entre os atletas. 
Em relação ao preparo físico, a maioria dos atletas $(97,72 \%)$ realizava alguma atividade física como forma de preparo físico para as competições. Doimo e Jimenez (2007) descreveram no seu estudo que $66,66 \%$ dos atletas realizavam alguma forma de preparo físico. $O$ estudo de Branício (2012) corrobora com a presente pesquisa descrevendo que $100 \%$ dos atletas realizavam algum tipo de preparo físico.

O trabalho de Doimo e Jimenez (2007) demonstrou que $27,08 \%$ dos atletas praticavam futebol apenas nos finais de semana como forma de preparo físico, enquanto $20,36 \%$ realizavam um condicionamento físico no mínimo três vezes por semana, seguidos por $16,66 \%$ que praticavam musculação duas vezes por semana. Em contrapartida, os resultados desse estudo demonstraram que $65,11 \%$ dos atletas realizavam corrida como forma de preparo físico, enquanto $55,81 \%$ realizavam alongamentos, seguidos por $46,51 \%$ que praticavam musculação, $18,60 \%$ que praticavam futebol e posteriormente $13,95 \%$ que praticavam outras atividades (natação, muay thay, treino de montarias e treino de prova de laço).

Doimo e Jimenez (2007) constataram que 20,36\% dos atletas tinham acompanhamento profissional durante a realização do preparo físico; o presente estudo demonstrou que $34,50 \%$ dos atletas realizavam preparo físico com acompanhamento profissional. Em contrapartida, o estudo de Branício (2012) afirmou que 50\% dos atletas tinham acompanhamento profissional no seu preparo físico.

Esse estudo descreveu que dos atletas que tinham acompanhamento profissional no preparo físico, $19,40 \%$ faziam com um educador físico, enquanto $6,46 \%$ com um fisioterapeuta, seguidos por $4,31 \%$ que tinham acompanhamento médico, 2,15\% de um massoterapeuta e 2,15\% com um educador físico associado a um fisioterapeuta. Já o estudo de Branício (2012) citou que 50\% dos atletas tinham acompanhamento de um educador físico ou um especialista na área.

De acordo com esse estudo, 93,18\% dos atletas consideraram importante a presença de um fisioterapeuta durante os treinos e competições, sendo que 38,63\% dos atletas afirmaram ter participado de competições onde havia a presença de um fisioterapeuta para assessorá-los. Em contrapartida, o estudo de Branício (2012) ressaltou que $100 \%$ dos organizadores do rodeio consideraram importante somente a presença de um educador físico para assessorar os atletas durante as competições, embora $50 \%$ afirmaram que havia a presença de um educador físico durante as competições que organizaram.

Branício (2012) enfatizou ainda que os itens obrigatórios de segurança são colete, calça de couro, espora e luva. Segundo esse estudo, 29,54\% dos atletas usavam apenas equipamentos de proteção individual obrigatórios, enquanto $25 \%$ usavam o capacete além dos equipamentos obrigatórios, outros $25 \%$ usavam o protetor bucal além dos equipamentos obrigatórios e apenas 20,45\% usavam além dos equipamentos obrigatórios capacete e protetor bucal.

O presente estudo referiu que $88,63 \%$ dos atletas sofreram algum tipo de lesão durante o tempo em que deveriam permanecer em cima do animal, sendo as lesões mais comuns a distensão muscular em região de coxa (13,33\%), distensão muscular em região de ombro $(11,42 \%)$, luxação de ombro $(6,66 \%)$, fratura em região de pé $(5,83 \%)$ e fratura em região de joelho e perna (ambas 5\%). Entretanto, no estudo de Bandettini et al. (2007) foi descrito que com $20 \%$ o cotovelo foi a região mais acometida, seguida do joelho (18\%) e posteriormente o punho com 16\%. O estudo de Doimo e Jimenez (2007) relatou que das 248 lesões referidas 84 foram abrasões, seguidas por 48 distensões, 34 contusões, 34 fraturas, 15 entorses e 19 luxações, sendo a coxa a região mais acometida com 24 ocorrências, acompanhadas do joelho (60), perna (36), quadril (20), pé (16) e tornozelo (14)

Comprova-se que os traumas de punho e cotovelo resultam devido à exorbitante força gerada para sustentar a posição do atleta durante a montaria, enquanto as lesões no joelho ocorrem através de quedas do animal (SOUZA et al., 2011).

De acordo com Vasconcelos et al. (2003) e Lau et al. (2013), o esforço exacerbado realizado pelos membros superiores pode levar à ruptura do tendão ou até mesmo do ventre muscular do peitoral maior, entretanto também pode ocorrer devido a uma queda do animal, quando o atleta cai sobre os braços estendidos.

Meyers e Laurent (2010a) observaram que a maioria das lesões (70\%) ocorreu durante o momento de desmontagem do animal. Em contrapartida, o presente 
estudo demonstrou que as lesões ocorreram mais durante o período em que o atleta deveria manter-se em cima do animal $(53,33 \%)$.

\section{CONCLUSÃO}

Tendo em vista o presente estudo, pode-se concluir que o preparo físico com acompanhamento profissional influenciou de forma significativa no rendimento dos atletas, reduzindo o risco de lesões e consequentemente o tempo fora de competições devido às lesões ocorridas, sendo que os atletas que não possuíam acompanhamento profissional durante o preparo físico demonstraram $33 \%$ a mais de chance de apresentarem algum tipo de lesão.

A maioria das lesões $(53,33 \%)$ ocorreu durante o tempo em que o atleta deveria se manter em cima do animal, o que reforça a importância de ser realizar um preparo físico adequado orientado por um profissional habilitado a fim de reduzir cada vez mais o índice de lesões que venham a ocorrer devido à relação dos impactos dos pulos e giros do animal e dos movimentos do atleta sobre o mesmo.

A lesão que mais acometeu o atleta durante o tempo em que deveria permanecer em cima do touro foi a distensão muscular em região de braço $(13,33 \%)$ e a lesão com menor ocorrência foi a fratura no maxilar $(0,83 \%)$. Já a lesão com maior incidência no momento do desmonte do animal foi a luxação no ombro $(10,47 \%)$ e a lesão com menor incidência foi a luxação em região de mão $(0,95 \%)$, todas capazes de deixar o atleta afastado das competições por um período significativo.

Vale ressaltar a escassez de material científico para a realização de pesquisas nessa área, levando em consideração que se trata de um esporte de alto risco que requer enorme habilidade e força do atleta; sugerese, desse modo, a realização de mais pesquisas sobre o desenvolvimento de mecanismos de proteção a fim de reduzir os riscos e consequências oriundas da prática desse esporte.

\section{REFERÊNCIAS}

BANDETTINI, A. L.; SALES, C. E. G. B.; TEOCHI, L. F.; BOFF, S. R. Índice de lesões e regiões mais acometidas em peões de montaria em touro da PBR Brasil. Rev Bras Fisioter., , v. 11, n. 1, p. 564, 2007.

BERGMASCHI, J. P.; MATSUDO, S. M.; MATSUDO, V. K. R. Relação da força de membros superiores e nível de atividade física com a prevalência de lesão e o desempenho de participantes de rodeio competitivo. RBCM., n. 14, v. 1, p. 53-58, 2006.

BRANÍCIO, C. R. A importância da preparação física para atletas de rodeio de montaria em touros. 2012. 91f. Monografia (Trabalho de Conclusão) - Universidade de Brasília, Curso de Licenciatura em Educação Física a Distância, Barretos, SP, 2012.

DOIMO, L. A.; JIMENEZ, M. V. O. Lesões referidas em atletas de montaria em touros/Related injuries in athletes of bull riding. Fisioter Bras., v. 8, n. 4, p. 239-242, 2007.

LAU, B. H. F.; BUTTERWICK, D. J.; LAFAVE, M. R.; MOHTAMI, N. G. Retrospective review of pectoralis major rupture in rodeo Steer Wrestlers. Adv Orthop., v. 2013, p.987910, 2013

MEYERS, M. C.; LAURENT, C. M. JR. The rodeo athlete: sport science: part I. Sports Med., v. 40, n. 5, p. 31-417, $2010 \mathrm{a}$

MEYERS, M. C.; LAURENT, C. M. JR. The rodeo athlete: injuries - part II. Sports Med., , v. 10, n. 40, p. 39-817, 2010b.

MEYERS, M. C.; STERLING, J. C.; SOURYAL, T. O. Radiographic findings of the upper extremity in collegiate rodeo athletes. Med Sci Sports Exerc., v. 35, n. 4, p. 7-543, 2003.

POWERS, S. K.; HOWLEY, E. T. Fisiologia do exercício teoria e aplicação ao condicionamento e ao desempenho. 6. ed. São Paulo: Manole, 2009, p. 36.

SERRA, R. A. de A.; TUBINO, M. J. G.; NOVAES, J. S. O rodeio como uma manifestação esportiva de identidade 
cultural do interior de São Paulo. Fit Perf J., v. 2, n. 6, p. 341-346, 2003.

SOUZA, A. B.; VERARDI, C. E. L.; NEIVA, C. M.; PESSÔA FILHO, D. M. Capacidade de força dos membros superiores em competidores de montaria em touros. Rev Col Pesq Educ Física, v. 10, n. 5, p. 59-64, 2011.

VASCONCELOS, U. M. R.; LEONARDI, A. B. A.; REIS, A. L.; CARVALHO FILHO, G.; CHUEIRE, A. G. Instabilidade ântero-inferior traumátiaca do ombro: procedimento de Bankart em atletas não profissionais. Acta Ortop Bras., v. 11, n. 3, p. 150-157, 2003.

Recebido em: 28 de novembro de 2015

Revisado em: 11 de fevereiro de 2016

Aceito em: 29 de fevereiro de 2016 